\title{
Ardinga no chat: a palavra como feromona
}

Maria Estela Guedes

\section{Ardinga in the chat: the word as feromon}


Resumo: A lenda da princesa Ardinga e D. Tedon, relativa ao período em que os mouros e os cristãos pelejavam pela posse da terra, e Lamego era a mais importante cidade islâmica de entre Tejo e Douro, é tema para reflexão sobre os estímulos do enamoramento: hoje, nos chats, como outrora, ouvindo contar, a palavra excita a imaginação e cria laços de afecto entre pessoas que não se conhecem fisicamente.

Palavras-chave: Ardinga. Lendas. Amor cortês.

\begin{abstract}
The legend of princess Ardinga and D. Tedon, who lived when Muslins and Christians were fighting for the land in Portugal, and Lamego was the main islamic city located between Tejo and Douro rivers, is the subject to think about love: today, as in the Middle Age, the word excites the imagination and creates emotional links between people that never met phisically.
\end{abstract}

Keywords: Ardinga. Legends. Courtly love. ca, Porto Alegre, v.10, n. 2, p.89-94, jul./dez. 2007. 


\author{
O amor é desejo de absoluto. \\ Platão \\ O amor paixão tem origem na acção do \\ corpo. \\ Descartes
}

As mouras encantadas são um tópico da nossa literatura, popular e erudita. Remanescem da cultura islâmica difundida na Península lbérica durante o período em que os árabes a habitaram (do século VIII ao século XIV), acopladas a mouras mais antigas.

Foram muitos séculos de permanência, o que permitiu legados e aperfeiçoamentos do que já existia que ainda hoje fazem parte da nossa civilização e cultura, quer espirituais quer materiais: o misticismo da nossa lírica trovadoresca, que subsistiu em poetas subsequentes; o traçado labiríntico das ruas, muito estreitas, ainda visível nos bairros de Alfama e Mouraria, em Lisboa; o avanço na química, matemática e medicina, sobretudo através da alquimia- os árabes deixaram-nos os números, facto bem conhecido. Na agricultura desenvolveram o sistema de irrigação, com uso de nora; introduziram os citrinos, a amendoeira, as ameixoeirase outras árvores de fruto; divulgaram a cultura de pomares, o modelo dos jardins-com cipreste, limoeiro, laranjeira, jasmineiro esempre aágua, em repuxo ou tanque. Nas artes decorativas, também parece virda mourama o gosto pelo ferro forjado, e pelo trabalho em metal ecouro. Porém, a mais bela herançaquea Península lbérica - ou o Al-Andaluz, como lhe chamaram - recebeu dos árabes, no que tocaà decoração de edifícios, foi o azulejo. O azulejo que, em Granada, no Alhambra, esse deslumbrante palácio árabe, me disseram significar "longe do azul": "azul lejos", longe do céu. Os muçulmanos usariam a beleza do azulejo para diminuir a distância entre elese Deus.

Ora esta maneira de usar a arte como oração, ou de falar directamente com Deus através de objectos que no caso teriam carga litúrgica, pode relacionar-se com o misticismo que passou da sua lírcapara a nossa, na ldade Média, contribuindo para constituir um culto à mulher, o amor cortês. O amor cortês exige louvores infindos à amada, distância em relação a ela, que a mulher pertença à classe social dominante, que seja casada, de preferência, e que o trovador não só lhe jure amor até à morte, mas que morra de amor por ela. O amor cortês tinha na Provença os seus poetas mais imitados, pertenceIhes o cânone. Na Primavera, época em que paravam as tempestades, o frio ia embora, os caminhos começavam a ficar transitáveis, comitivas de trovadores, músicos e bailadeiras iam de castelo em castelo, poressa Europa fora, a pé ou a cavalo, apresentar nas cortes as suas novidades poéticas e musicais. Oamor cortês, como o nome indica, e o estatuto social da mulher amada já sugeriu, era próprio da corte, constituindo algo como um ritual. Daí que um dos trovadores portugueses, o rei D. Dinis, a certa altura critique esta lírica por ser estereotipada, Ihe faltar a sinceridade, dizendo que os provençais sabiam muito bem trovar, mas não era com amor, pois só trovavam na Primavera; por isso não sofriam de paixão verdadeira como ele, tão grande que o havia de matar:

Proençaes soem mui bem trobar e dizem eles que é com amor; mais os que trobam no tempo da frol e nom em outro, sei eu bem que nom am tam gram coita no seu coraçon qual m'eu por mia senhor vejo levar.

Pero que trobam e sabem loar sas senhores o mais e o melhor que eles podem, sõo sabedor que os que trobam quand'a frol sazom á, e nom ante, se Deus mi perdom, nom am tal coita qual eu ei sem par. 
Ca os que trobam e que s'alegrar vam eno tempo que tem a color a frol consigu'e, tanto que se for aquel tempo, logu'em trobar razom nom am, nom vivem em qual perdiçom oj'eu vivo, que pois m'á de matar.

(DON DINIS, 2005).

Estes elementos do amor cortês aparecem na lenda de Ardinga, a princesa moura, e D. Tédon, o cavaleiro cristão. A narrativa tem por lugar central o castelo de Lamego e a região que vai até S. Pedro das Águias e Granja do Tédo, em Tabuaço. É a rota de Ardinga, fugitiva em busca do seu amado, fundador da Granja do Tédo.

Esta lenda faz parte de uma série de textos fundadores da cultura cristã na parte mais ocidental da Europa, em oposição ao islamismo. Relata como é forte o amor da muçulmana pelo cristão, e como é bárbara a cultura islâmica ao condená-la à morte por isso. As religiões confrontam-se, mas no horizonte entrevê-se a utopia da aliança entre as duas culturas, como sugere Isabel Oliveira (2007), aliança que se verificou efectivamente. No caso da lenda, é evidente a natureza do amor, trespassada do idealismo que a aproxima do amor cortês, impregnado pelo misticismo da lírica árabe.

Que diz a lenda, afinal? Não é preciso reescrever o que mil vezes foi escrito. Vejamos o que diz o site da Câmara Municipal de Tabuaço ([2007?]):

Segundo a lenda, D. Thedon e D. Rosendo, cavaleiros cristãos que, nos princípios do séc. $\mathrm{XI}$, combatiam a mourama instalada na vertente do Douro, passaram por esta terra a que hoje chamamos de Granja do Tedo e aqui se quedaram por algum tempo. Agradado com o sítio, D. Thedon assentou aqui residência e construiu casa e granja. Tal era a valentia e tais os feitos de $D$. Thedon em combate que acabou por conquistar também o coração de uma princesa moura, Ardinga ou Ardínia, fiIha de D. Alboazan, rei mouro de Lamego, que os cavaleiros combatiam. Por amor a D. Thedon, a princesa moura, acompanhada de uma dama de companhia, fugiu para a ermida de S. Pedro das Águias, à esquerda do rio Távora, onde o monge Gelásio a recebeu, instruiu e converteu, pelo baptismo, ao Cristianismo, para poder casá-la com D. Thedon. Alboazan, o rei mouro, ao saber da fuga da filha, tomou-se de ira e seguiu Ardinga até ao santuário, onde a matou e atirou ao rio Távora, antes que a sorte a tivesse unido alguma vez ao cavaleiro. Ao receber tal notícia, D. Thedon jurou morrer solteiro e nunca mais descansar a espada na luta contra os sarracenos. Diz a história que o rei Alboazan, morto por D. Thedon, foi a enterrar no monte vizinho, que ficou a chamar-se Monte Rei. O cavaleiro, esse, lutou corajosamente até que, apanhado à traição, foi morto em combate e o seu corpo mutilado atirado às águas do rio que hoje usa o seu nome: o rio Tedo.

O que há de actual no amor cortês? Ele espelha-se no desejo de quem tecla no chat, contrariando a tendência de alguns cientistas para conceberem o amor como reacção bioquímica de um às feromonas do outro. Ardinga apaixona-se por ouvir contar, ela nunca chega a encontrar-se com o seu cavaleiro. Dir-se-á que isto é lenda, e que a lenda não faz prova de paixão. Bom, poderá nenhum facto dela ter ocorrido na História, mas a lenda faz prova, sim. Faz prova de que concepções altamente idealizadas do amor circularam no momento da fundação de nacionalidades, e em especial circularam em épocas de confrontação física entre povos de características étnicas diferentes, como se a sua força pudesse contrariar a guerra e estabelecer a paz entreos adversários. Mais:como seoenamoramento pairasse no horizonte de desejo de exércitos de desconhecidos.

O que caracteriza o relacionamento entre duas pessoas que não se conhecem, a não serenquanto criadoras de uma comunicação amoro- 
sa, é o facto de o seu envolvimento não ter na origem estímulos físicos provenientes do outro. Esse envolvimento sem corpo, titilado por uma sensualidade sem suporte físico, entra no quadro da paixão definida por Denis de Rougemeontem "L'amour et l'Occident', em que o desejante ama o próprio amor:

\begin{abstract}
Passion veut dire souffrance, chose subie, prépondérance du destin sur la personne libre et responsable. Aimer l'amour plus que l'objet de l'amour, aimer la passion pour elle-même, de l'amabam amare de saint Augustin jusqu'au romantisme moderne, c'est aimer et chercher la souffrance. Amour-passion: désir de ce qui nous blesse, et nous anéantit par son triomphe. (ROUGEMONT, 1972).
\end{abstract}

Alguns consideram que a rede dos afectos, $\mathrm{e}$ centralmente nela oerotismo, é um fenómeno estritamente bioquímico, dependendo de estímulos como cheiros, as jáconsagradas feromonas do nosso tempo intelectual. De tal modo que se tornou moda o recurso à linguagem da ciência para atrair à perfumaria o mercado dos amores. Aprecie-se esteanúncio:

Imagine um afrodisíaco natural provado cientificamente atrair mulheres. O nosso Concentrado de Feromonas de Androstenona é exactamente isso! As mulheres subconscientemente detectam este produto e sentem-se instantaneamente atraídas por si! Encomende já!" (INTELLIDUS, 2006).

Defendo, baseada na experiência de vidae de leitura, que o erotismo, podendo excitar-se com feromonas, é, à partida, entre um par de desconhecidos, uma rede de estímulos gerados pela imaginação. Enamoramo-nos tanto mais, quanto mais formos imaginativos. Oamoré filho do mundo emocional e intelectual e não tanto de aromas que, em situação neutra, ou de relacionamento amoroso sadio, são emgeral desagradáveis.

Por outro lado ainda, gostava de deixar no vento a verificação deque nada do que se passacom oamorénovo. A Redeénova, novos os computadores, vanguardistas os chats e messengers, porémo apaixonamento por teclar com outro é igual ao das madrinhas de guerra pelos seus soldados, que tem por suporte apenas o papel em que se escrevem cartas; é igual ao das cartas que escrevem os que casam por procuração; o enamoramento no chat, entre desconhecidos, é igual ao amor dos que se apaixonam por verem um medalhão com o rosto do futuro consorte; eéigual ao amor dos que se apaixonam por ouvir contar. Ardinga apaixonou-se por ouvir contar, tal como Chaariar poupou a vida a Xerazade por esta o ter encantado com histórias ao longo das mil e uma noites que durou o seu enamoramento.

"E no dia seguinte...". "No dia seguinte", eis um poderosíssimo anzol para prender corações - a palavra. É a palavra que move a imaginação. Sea palavra for cantada, então... Quantos de nós não se apaixonaram loucamente pela Madonna, pelo Elvis, pelo Roberto Carlos? Mas não é preciso que a palavra seja musicada. Nós apaixonamo-nos, de preferência na juventude, pelo Alain Delon, pela Angelina Jolie, pelo Brad Pitt. .. Oraque feromonas podem ter eles lançado ao écran? Justamente, não lançaram nenhumas, as suas substâncias apelativas não são bioquímicas, sim verbais e imagéticas.

Éapalavraque gera envolvimento amoroso entre Ardinga e D. Tedon. Exactamente como no messenger e no chat a imaginação de dois jovens entra em ebulição e eles se apaixonam. Depois poderão marcar encontro e o amor resistir ou não à prova das feromonas. Porque é muito forteoembate corporal, e as bioquímicas e órgãos nem sempre se aceitam unsaosoutros. Vantagem dapalavra sobreo beijo: por muito que faça ranger os dentes, não cheira maldaboca. 
teoria \& prática Porto Alegre, v.10, n.2, jul./dez. 2007. ISSN 1516084 X

\section{Referências}

CÂMARA MUNICIPAL DE TABUAÇO. Lendas e tradições: lenda de D. Thedon. Tabuaço: [2007?].

Disponível em: <http://cm-tabuaco.pt/cmtab/

index.php?option=com_content\&task=view\&id=21\&ltemid=30>. Acesso em: 2007.

DON DINIS. Cantiga. In: ESCOLA SUPERIOR DE EDUCAÇÃO DE VISEU. Quadro-síntese comparativo das cantigas de amigo, amor e escárnio. Viseu: 2005. Disponível em: <http://www.esev.ipv.pt/ servicos/upload\%5Cma\%5C1213\%5C5.Quadro_s\%C3\%ADntese_poesiatrovadoresca.doc>. Acesso em: 2007.

INTELLIDUS. apaixonante.com. Porto: 2006. Disponível em: <http://www.apaixonante.com/>. Acesso em: 2007.

OLIVEIRA, Isabel. Ardínia: um passado presente. In: COLÓQUIO INTERNACIONAL DISCURSOSE PRÁTICAS ALQUÍMICAS, 7, 2007, Lamego. Anais... Lamego: CICTSUL, 2007. Disponível em: <http:// www.triplov.com/Coloquio_07//sabel-Oliveira/index.html>. Acesso em: 2007.

ROUGEMONT, Denis de. L'amour et l'occident. Paris: Plon, 1972.

Recebido em setembro de 2007

Aceito para publicação em outubro de 2007

\section{Maria Estela Guedes}

Membro da Associação Portuguesa de Escritores e do Centro Interdisciplinar de Ciência, Tecnologia

e Sociedade da Universidade de Lisboa.

Directora do TriploV (www.triplov.com).

estela@triplov.com 